\title{
Stage B Prostate Cancer
}

National Cancer Institute

\section{Source}

National Cancer Institute. Stage B Prostate Cancer. NCI Thesaurus. Code C7554.

Tumor is clinically palpable but confined to the prostate. -- 2004 